\title{
Mechanical threshold of cementitious materials at early
} age

\author{
J.M. Torrenti ${ }^{1,2}$ and F. Benboudjema ${ }^{2}$ \\ (1) IRSN, Fontenay-aux-Roses, France \\ (2) LMT, ENS de Cachan, France
}

\begin{abstract}
At early age, the mechanical characteristics of concrete, such as Young's modulus, follow a rapid rate of change. If strains are restricted or in the event of strain gradients, tensile stresses are generated and there is a risk of cracks occurring. Besides relaxation, change in Young's modulus as a function of the degree of hydration is a major parameter for the modeling of this phenomenon. In this evolution, a threshold of the degree of hydration has to be taken into account, below which concrete displays negligible stiffness. For cement pastes, a simplified hydration model shows that percolation of the solid phases depends on the $\mathrm{w} / \mathrm{c}$ ratio, which is in accordance with experimental results. On the other hand, for mortar or concrete, the presence of aggregates means that the solid volumetric fraction is such that percolation is observed before hydration occurs. Therefore another parameter is introduced: cohesion due to hydration products. By coupling our model with a finite-element code (CAST3M), it is shown that the threshold for Young's modulus in mortar is almost independent of the $\mathrm{w} / \mathrm{c}$ ratio, which is in accordance with experimental results.
\end{abstract}

\section{RÉSUMÉ}

Au jeune âge, les caractéristiques mécaniques du béton, telles que le module d'Young, suivent une évolution rapide. Si les déformations sont gênées, ou s'il existe des gradients de déformation, des contraintes de traction sont générées et il y a un risque de fissuration. La variation du module d'Young en fonction du degré d'hydratation est un paramètre majeur pour la modélisation de ce phénomène. Dans cette évolution, un seuil d'hydratation en deçà duquel la rigidité du béton est négligeable doit être pris en compte. Pour des pâtes de ciment, un modèle simplifié d'hydratation montre que la percolation des phases solides dépend du rapport eau sur ciment, ce qui est en accord avec les résultats expérimentaux. Pour les mortiers et les bétons, la présence des granulats a pour conséquence que la percolation de la fraction solide est observée même pour un degré d'hydratation nul. C'est pourquoi nous introduisons un autre paramètre : la cohésion due aux hydrates formés. En introduisant notre modèle dans un code de calcul aux éléments finis (CAST3M), nous montrons que le seuil d'hydratation du module d'Young du mortier est pratiquement indépendant du rapport eau sur ciment, ce qui est en accord avec les résultats expérimentaux.

\section{INTRODUCTION}

Modeling the behavior of concrete at an early age is a major industrial problem in civil engineering, because the heat given off by the hydration of cement leads to thermal strains. If these strains are restricted, or if a gradient occurs between the skin and core of the structure, there is a considerable risk of cracking. In order to control this cracking, accurate modeling of the strains and stresses is required, especially if it is to be predictive.

Mechanical behavior - one of the components of this type of model - involves a threshold of the degree of hydration $\alpha_{0}$ below which the strength of the material can be neglected. This behavior can be expressed by the relationship between the strength $f_{c}$ of the concrete and its Young's modulus $E_{c}$ to the degree of hydration $[3,6,11,13]$ :

$f c(\alpha)=f c(\alpha=1) \cdot\left(\alpha-\alpha_{0}\right) /\left(1-\alpha_{0}\right)$

where $\alpha$ is the degree of hydration of the cement; and if $E_{c}(\alpha)=\mathrm{k} \mathrm{fc}(\alpha)^{\beta}$ then $E_{c}(\alpha)=E_{c}(\alpha=1) \cdot\left[\left(\alpha-\alpha_{0}\right) /\left(1-\alpha_{0}\right)\right]^{\beta}$

Considering the relation between the strength and the degree of hydration, the threshold $\alpha_{0}$ is the intersection of the regression line of this relation and the x-axis. $\alpha_{0}$, which is a genuine mechanical percolation threshold [1] plays therefore a key role in the prediction of generated stresses. Below $\alpha_{0}$ the stiffness is not equal to zero but can be neglected in the stress calculation. 


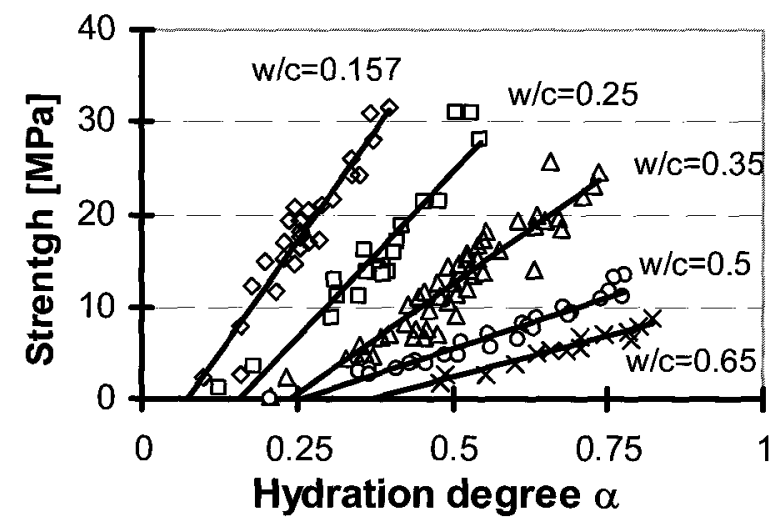

Fig. 1 - Changes in the strength of cement pastes of various w/c ratios - Taplin's experiments (quoted by Byfors [6]). Changes in strength are expressed as a function of the degree of hydration.

Furthermore, in order to obtain a truly predictive concrete behavior model, the formulation and, more particularly, the $w / c$ ratio must be taken into consideration. Bernard [3] proposed a threshold $\alpha_{0}$ that varied with the w/c ratio, observing that the grains of cement suspended in the water percolated (in that they were in contact) for a given value of degree of hydration. In qualitative terms, this is in good agreement with Taplin's experimental results (quoted by Byfors [6]) obtained from cement pastes with various w/c ratios (Fig. 1), provided that the $w / c$ ratio is relatively high. As demonstrated further on, this solid phase percolation is not adequate for low $\mathrm{w} / \mathrm{c}$ ratios.

In addition, results obtained for mortar - Fig. 2 (Catharin quoted by [6]) and concrete - Fig. 3 [6] seem to indicate that the mechanical threshold is far less dependent on the w/c ratio, this effect obviously being related to the presence of aggregates. The aim of this study is to explain the above result and model the phenomenon. After considering the results for cement paste, it is demonstrated that the approach to the percolation threshold based on grain contact (solid phase percolation like in a sand) is not sufficient. A simple hydration model is used to show the impact of hydrates, which are gluing the grains, on mechanical behavior at early age (mechanical percolation). Lastly, the role played by aggregates is considered.

The curing conditions are not taken into account in ours simulations because the effect of common temperature (e.g. from $0^{\circ} \mathrm{C}$ to $40^{\circ} \mathrm{C}$ ) and relative humidity is negligible on the value of the threshold $\alpha_{0}[6]$.

\section{MODEL OF HYDRATION IN A CEMENT PASTE}

\subsection{Solid-phase percolation model}

The purpose pursued here does not call for a very accurate hydration model. This work could, in fact, be repeated with a more sophisticated hydration model without affecting the conclusions reached. The model used was proposed by [10]. It was assumed that the hydrates occupied a volume equal to 2.31 times that of the reactants: $V_{\text {soldds }}=(1+2.31 \alpha) /(1+3.2 \mathrm{w} / \mathrm{c})$.

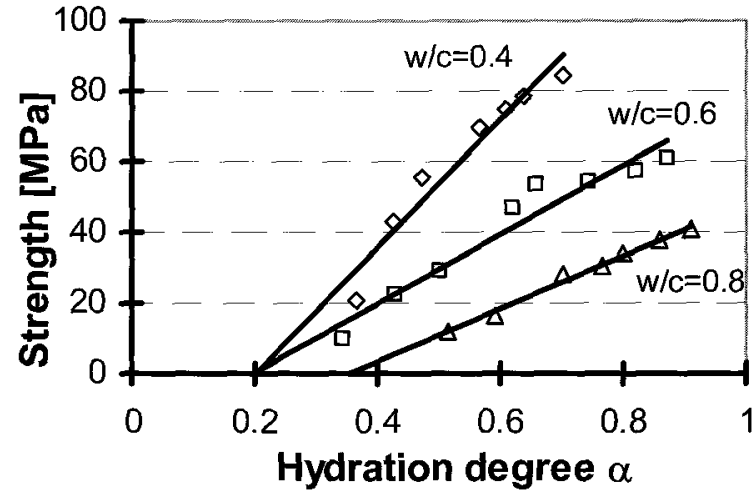

Fig. 2 - Changes in the strength of mortar of various $w / c$ ratios (Catharin, quoted by Byfors [6]).

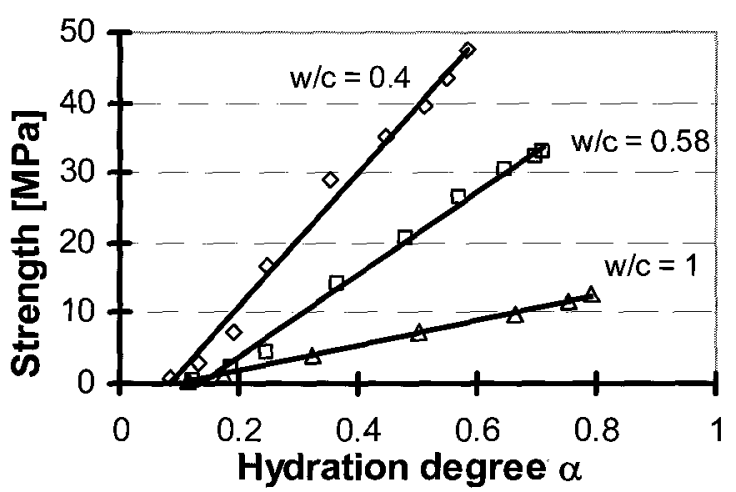

Fig. 3 - Changes in the strength of concrete of various w/c ratios [6]

It is straightforward to calculate from this simple model the volume of each microstructural component of a cement paste for a given $w / c$ ratio. The solid particles were then distributed randomly on a two-dimensional $100 \times 100$ mesh. The size of one pixel is $10 \mu \mathrm{m} \times 10 \mu \mathrm{m}$. Fig. 4 shows an example of this mesh. The percolation theory shows that percolation is observed when the solid volumetric fraction exceeds a value depending on the degree of connectivity [10]. In our case we consider a two dimensional square lattice where the central square could be connected to its 8 neighbors. A "burning" algorithm can be used to check this percolation threshold (Fig. 5). Note also that the percolation threshold is not the same for a 2D or a 3D lattice and that the probability of percolation also depends of the size of the considered lattice (Fig. 6). As the microstructure is a random construction, many test trials must be taken. Fig. 7 shows the results obtained for 100 test shots of the microstructure at each stage of the hydration reaction.

This type of model clearly demonstrates that the percolation threshold depends on the $\mathrm{w} / \mathrm{c}$ ratio. However, it also shows that below a certain w/c value, percolation occurs even when $\alpha=0$. Under experimental conditions, the cement paste with a w/c ratio of 0.157 studied by Taplin requires a degree of hydration equal to about 0.15 for mechanical percolation to occur. It would seem that these differences are due to the fact that percolation as defined above is not the same phenomenon as the mechanical percolation defined in the introduction, for even though the particles touch, there is no cohesion between them, and this leads to the formation of a soft solid. For this 


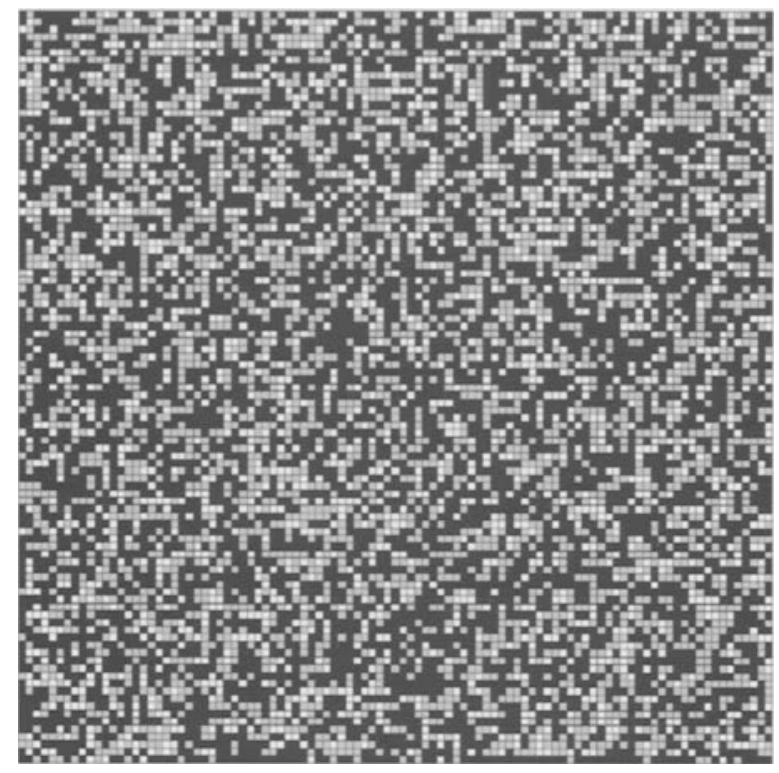

Fig. 4 - Example of structure generated - cement paste $\mathrm{w} / \mathrm{c}=0.5$ and $\alpha=0.2$. The gray dots represent anhydrous cement, the white dots hydrated cement, and the black dots water.

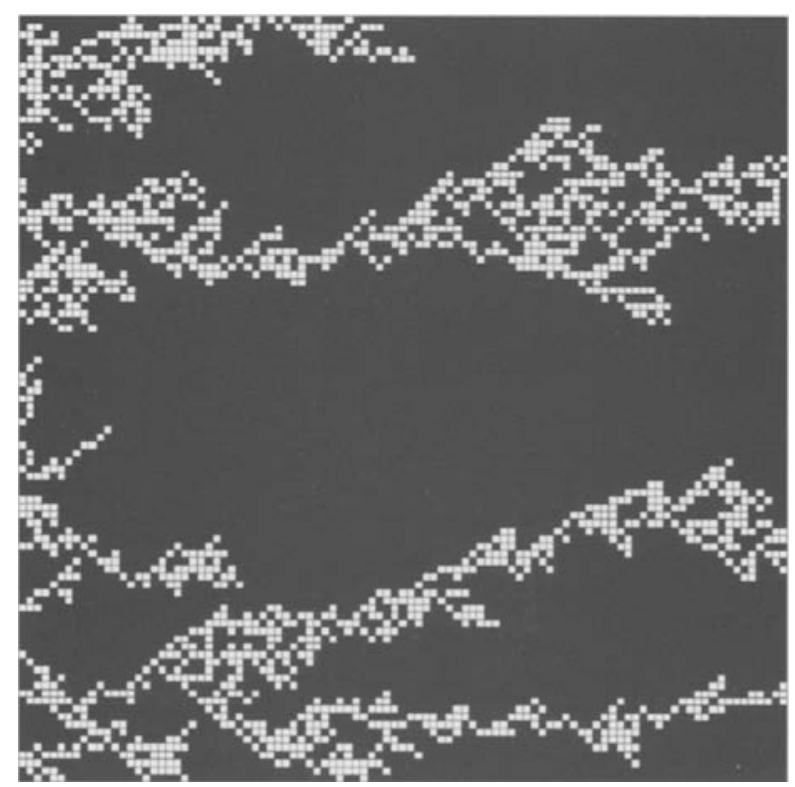

Fig. 5 - Percolation revealed by a "burning" algorithm for a cement paste where $w / c=0.5$ and $\alpha=0.2$. The solid particles are flammable. The left-hand column is set on fire, and the fire spreads as soon as two particles come into contact. Percolation is considered to occur when the fire can spread from one side of the test specimen to the other.

reason, another ingredient needs to be added to our model, as discussed in the following section.

\subsection{Mechanical percolation model}

Examination of the setting process in a cement paste reveals a transition between a viscoelastic liquid and a viscoelastic solid $[4,7,12]$. Mechanical percolation occurs when enough hydrates in the Portland cement paste has been formed to ensure cohesion between the solid grains [9]. This was the principle used here.

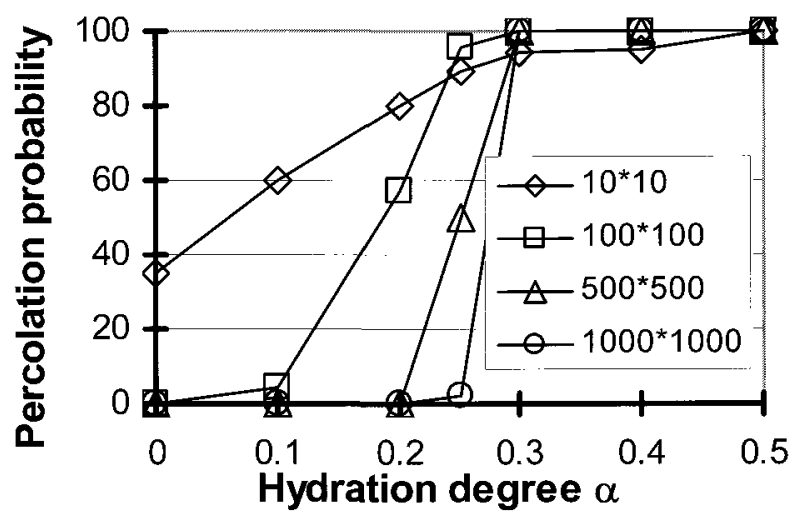

Fig. 6 - Influence of the lattice size on the probability of percolation, $w / c=0.5$.

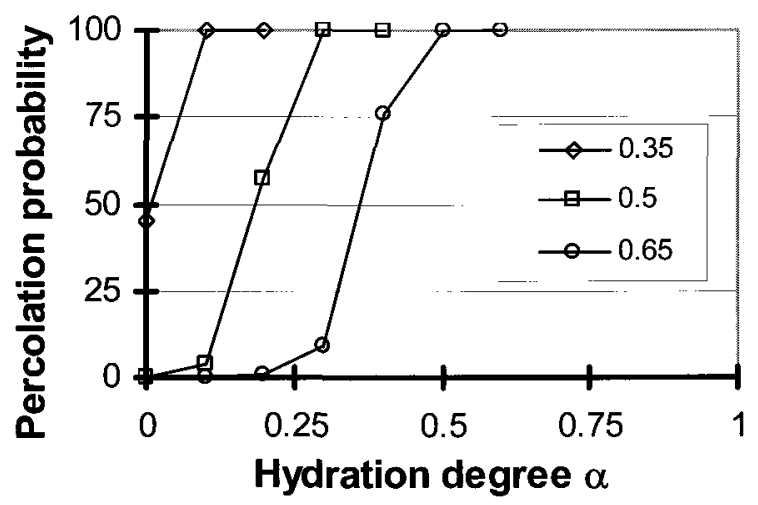

Fig. 7 - Changes in percolation probability as a function of the degree of hydration $\alpha$, for various w/c ratios. For $w / c=0.157$ and $w / \mathrm{c}=0.25$ we obtain percolation even when $\alpha=0$ (lattice size $100 \times 100$ ).

Using images of the microstructure generated according to the method defined above (see Section 2.1 and Fig. 4), a mesh was created for a finite-element calculation. Each pixel is replaced by an 8-nodes quadrangular element. It was considered that all materials displayed elastic behavior. The values adopted for the calculation are shown in Table 1. These are mean values, obtained from measured ones by nanoindentation on residual clinker and hydrated phases in a cement paste [14]. Moreover, we assume that the pores have a very low stiffness and a Poisson's ratio close to 0.5 . The material parameters are given in Table 1 .

\begin{tabular}{|c|c|c|c|c|c|}
\hline \multicolumn{6}{|c|}{$\begin{array}{l}\text { Table } 1 \text { - Mechanical properties of each cement paste } \\
\text { phase }\end{array}$} \\
\hline \multicolumn{2}{|c|}{ Anhydrous grains } & \multicolumn{2}{|c|}{ Hydrates } & \multicolumn{2}{|c|}{ Pores } \\
\hline$E[\mathrm{GPa}]$ & $v$ & $E$ [GPa] & $v$ & $E[\mathrm{~Pa}]$ & $v$ \\
\hline 135 & 0.2 & 25 & 0.2 & 1000 & 0.4999 \\
\hline
\end{tabular}

Note that we do not take into account here the capillary forces due to autogeneous shrinkage particularly for low w/c ratio and that could add some cohesion to the granular skeleton.

The link between each pixel was made using interface elements of zero thickness. In this type of element, the stressstrain relationship was replaced by that showing the stress transmitted across the interface as a function of the relative displacement between the two contact surfaces. The idea is 
here to take into account the cohesion brought by the hydrated phase.

The mechanical properties of the interface elements depend on the type of elements coming into contact. Two types of elements were distinguished:

- Cohesive interface elements: these are responsible for the material cohesion. They are found as soon as a hydrated particle came into contact with the interface element. Their behavior is elastic.

- Non-cohesive elements: these displayed no cohesion and are found when no hydrated particles come into contact with the interface element. Their behavior followed that of an elastic material in compression, a perfect brittle material in tension, and a perfect elastoplastic material in shear conditions (see Fig. 8). The Mohr-Coulomb criterion is adopted.

As suggested at the beginning of this section, the hydrated particles are responsible for the material cohesion and played a "bonding" role. Tension parameters are shown in Table 2. Only tension values are shown as the sole aim here was to determine whether a material was cohesive.

High values for the Young modulus are adopted, so as interface elements do not influence the global stiffness of the material.

The displacement of the microstructure was then blocked on the left-hand side $\left(U_{x}\right)$ and at the bottom $\left(U_{y}\right)$. The horizontal displacement at the right face is free, but identical in all nodes. The top side was then subjected to a tensile displacement $U_{\text {sup }}$ (see Fig. 9). A typical mesh is

\begin{tabular}{|c|c|c|}
\hline Table 2 - Mechanical properties of interface elements \\
\hline Cohesive elements & \multicolumn{2}{|c|}{ Non-cohesive elements } \\
\hline$E_{t}[\mathrm{GPa}]$ & $E_{t}[\mathrm{GPa}]$ & $f_{t}[\mathrm{MPa}]$ \\
\hline $10^{8}$ & $10^{8}$ & 0 \\
\hline
\end{tabular}

also displayed in this figure, for $w / c=0.35$ and $\alpha=0.3$. A two-dimensional $50 \times 50$ mesh is used here.

The finite-element calculation was then performed using the Cast $3 m$ finite element code developed by the CEA. Results were analyzed in terms of force $F_{\text {sup }}$ - displacement $U_{\text {sup }}$ curves at the top side. If the secant stiffness of the test specimen exceed a threshold value (fixed here at $1 \mathrm{MPa}$ ), it is considered that the material is cohesive and that mechanical percolation has occurred. For identical w/c ratio and degree of hydration values, 10 shots were taken of the microstructure to test the mechanical percolation. The number of identical tests and the size of the lattice are reduced comparatively to the solid phase percolation, since the finite elements calculations are much more time consuming.

In order to illustrate the finite elements calculus, typical force-displacement curves are plotted in Fig. 10, for w/c = $0.35, \alpha=0.3$ (probability to percolate equal to $0 \%$ ) and $\alpha=$ 0.4 (probability to percolate equal to $100 \%$ ).

Fig. 11 summarizes the percolation results obtained at each stage of the hydration reaction.

From the comparison between Figs. 1 and 11, the following remark can be drawn. The w/c ratio affects considerably the degree of hydration threshold when mechanical percolation occurs. More the $w / c$ ratio is important, more the threshold value is important. This is consistent with experimental results. Moreover, Fig. 11

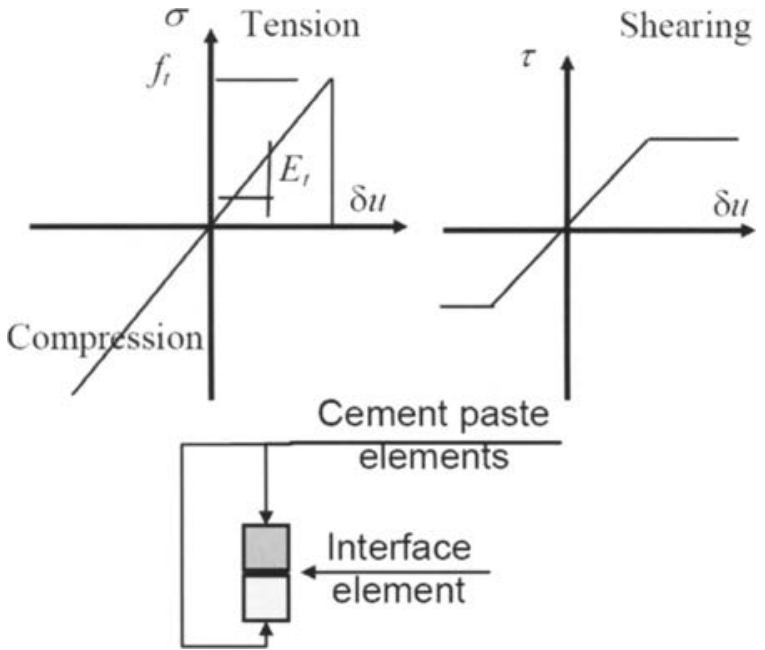

Fig. 8 - Behavior law of interface elements and their location.

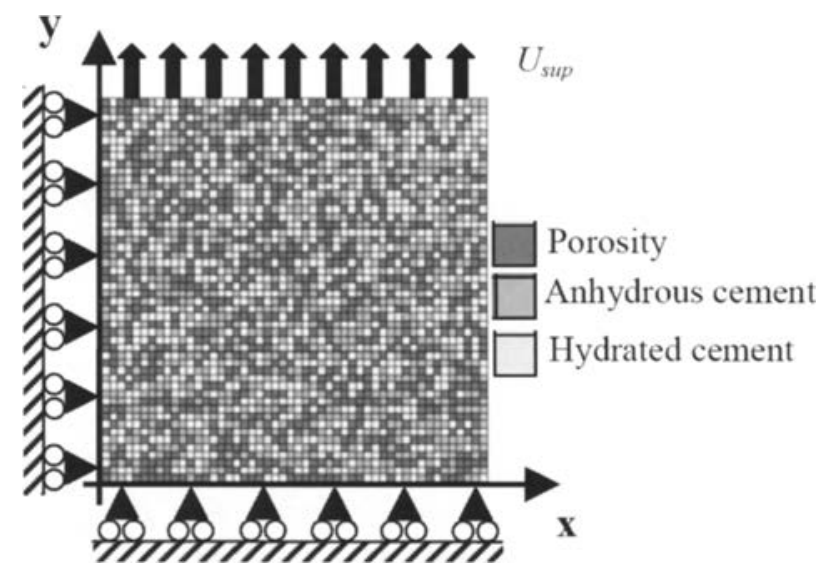

Fig. 9 - Boundary conditions for numerical calculations and typical mesh of a cement paste ( $w / c=0.35$ and $\alpha=0.3$ ).

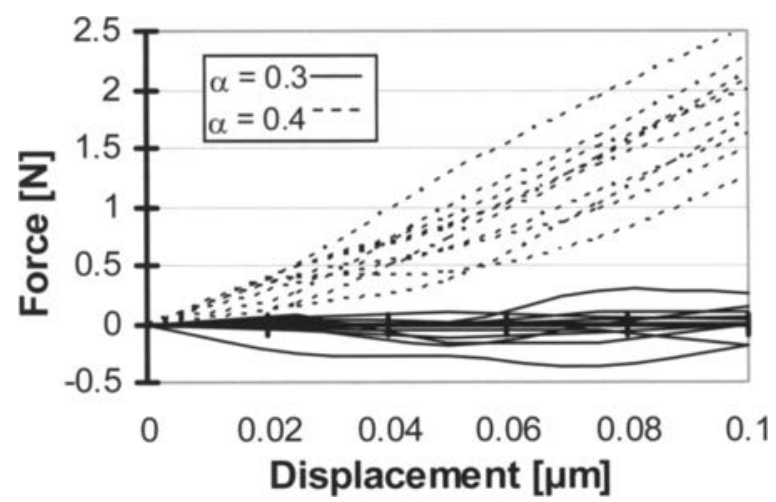

Fig. 10 - Force-displacement curves for a non-percolated $(\mathrm{w} / \mathrm{c}=$ 0.35 and $\alpha=0.3)$ and a percolated state ( $w / c=0.35$ and $\alpha=0.4)$.

shows that the transition between a non-percolated state to a percolated one occurs within a short transition period.

Furthermore, it highlights the fact, that the mechanical percolation threshold can not be evaluated by a grain contact approach (solid phase percolation, section 2.1). Indeed, a grain contact does not imply a cohesion between the grains (for $\mathrm{w} / \mathrm{c}$ $=0.157$ and $\alpha=0.05$, a solid phase percolation occurs, see 


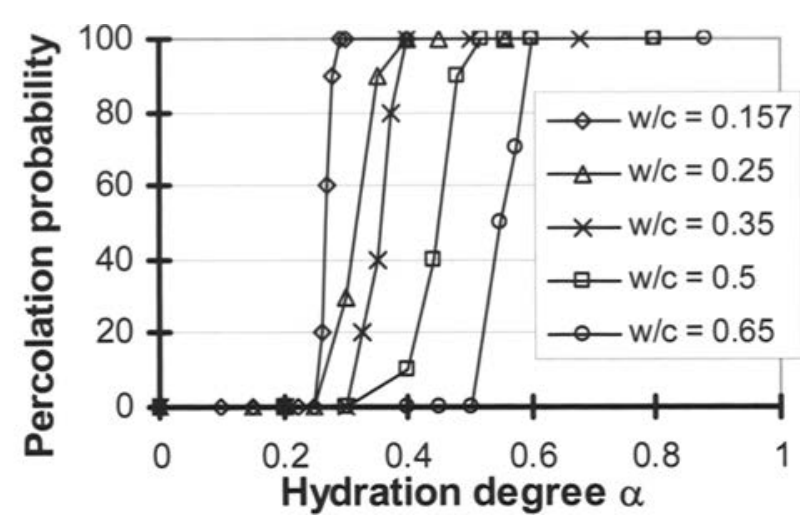

Fig. 11 - Changes in percolation probability of a cement paste as a function of the progress of the hydration reaction, for various $\mathrm{w} / \mathrm{c}$ ratios.

Fig. 1, which is not the case of mechanical percolation).

Since the microstructure of the cement paste is generated randomly, the results obtained may be different if an "intelligent" algorithm (as CEMHYD3D [2] or HYMOSTRUC [5] for instance) is used. However, obtained results show a smooth evolution of the percolation probability with respect to the degree of hydration for various $w / c$ ratios. Therefore, it can be expected that the construction algorithm of the cement paste microstructure does not influence qualitatively the obtained results.

\section{MORTAR HYDRATION MODELLING}

The next section focuses on the case of mortar. After defining the granular phase, this section describes how models are generated. Then, an analysis of mortar behaviour is performed.

\subsection{Definition of the granular phase}

The total volumetric proportion of sand in the mortar was $66 \%$. This volumetric proportion and the aggregate distribution considered are the same as that found in standardized French mortar (NFP 15-403). This distribution is shown in Fig. 12. Of course, the results of our simulations will be changed if we change the volumetric proportion of sand.

\subsection{Mortar generation}

The structure of the granular phase of the mortar was generated using the algorithm employed by the NIST CEMHYD3D hydration model [10]. Only two phases were considered during the building of the mortar: the granular and the cement paste phase. We do not consider here the effect of the interfacial transition zone (ITZ) which could exist particularly for high $w / c$. Taking into account ITZ will change the values of strength and stiffness but not affect the mechanical percolation significantly.

The granular phase was generated by distributing grains of sand one after the other and at random. For large volumetric proportions, as in the case addressed here, it may be difficult to distribute all the grains of sand. For this reason, it is necessary to start to fill the structure with the largest grains. Then the cement paste (including hydrates, anhydrous grains and the

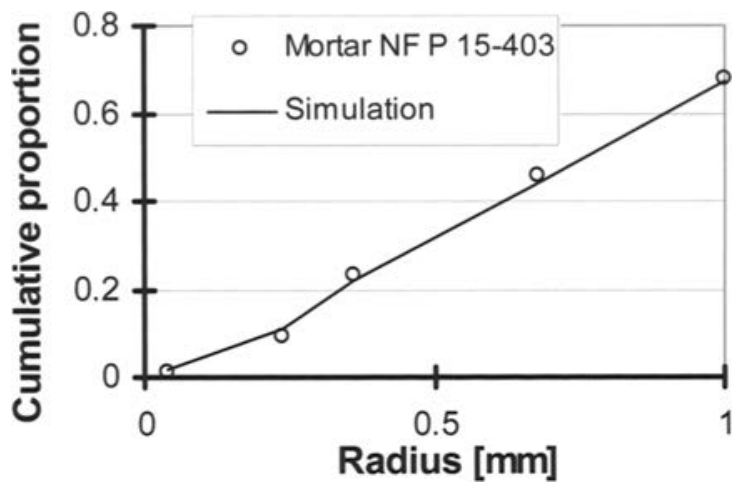

Fig. 12 - Cumulative volume proportion of sand grains in mortar.

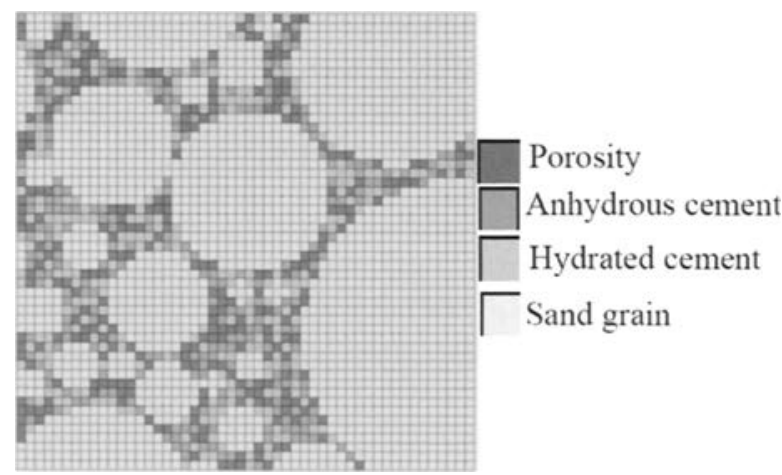

Fig. 13 - Typical mesh of a mortar $(w / c=0.35$ and $\alpha=0.3)$.

porosity) was generated randomly as was the case previously. The result was a mortar cube of $50 \times 50 \times 50$ pixels. One pixel corresponds to $40 \mu \mathrm{m} \times 40 \mu \mathrm{m} \times 40 \mu \mathrm{m}$. Random plane sections of this cube were used, implying that the surface proportion of aggregates was also random, but on average equal to the volumetric proportion. One of these sections is shown in Fig. 13.

\subsection{Models}

In percolation theory, it can be seen that the size of the particles required to fill a space has an obvious effect on the percolation phenomenon [8]. This is because the pixels representing one aggregate are correlated. However, the volumetric fraction of sand added to the mortar leads to a very high volumetric fraction of solid, and percolation, as defined in Section 1.1 occurs before any hydration, even at relatively high w/c ratios (up to 0.8). However, the same criticism can be raised here as with the cement paste: the fact that the solid grains touch each other does not necessarily guarantee material stiffness. It is therefore essential to adopt the same approach as that defined in Section 2.2 .

The model developed in Section 2.2 was therefore adopted, adding a granular phase (granite sand) of stiffness $\mathrm{E}=49 \mathrm{GPa}$ and a Poisson's ratio $v=0.2$. The rules for distributing the interface elements were almost the same:

- No interface elements were added between granular pixels;

- A cohesive interface element is used between a granular pixel and a C-S-H one (see Table 2);

- A non-cohesive interface element is used otherwise (see Table 2). 


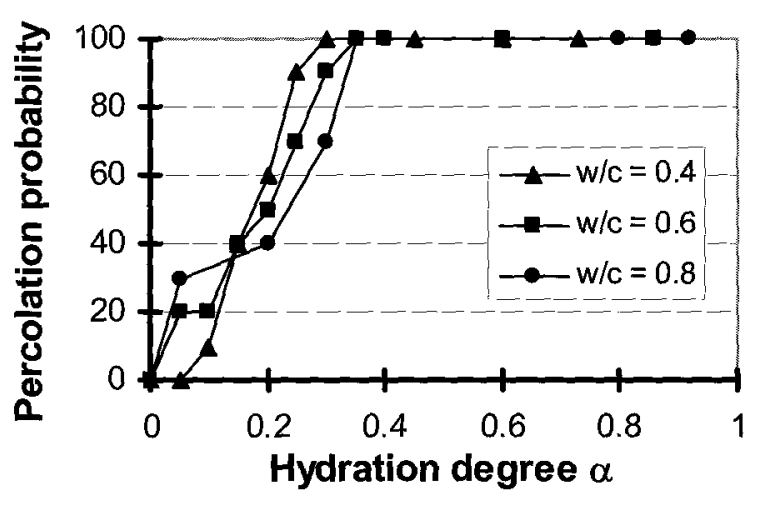

Fig. 14 - Changes in percolation probability of a mortar as a function of the progress of the hydration reaction, for various w/c ratios.

As in the case of cement paste (section $\S 2.2$ ), 10 shots were taken of the microstructure to test mechanical percolation, for identical $w / c$ ratio and degree of hydration values.

Fig. 14 shows the results obtained at each stage of the hydration reaction.

The results for our mortar are completely different from the ones obtained with the cement paste (Fig. 11). Indeed, the degree of hydration threshold does not depend anymore upon the $\mathrm{w} / \mathrm{c}$ ratio. This is qualitatively consistent with experimental results of Catharin (Fig. 2). Furthermore, the threshold value is much less important, since the solid content is higher.

Moreover, the transition between a non-percolated state to a percolated one is not as marked as in the case of the cement paste. Note that in the case of a mortar with a lesser volumetric proportion of sand the influence of the $\mathrm{w} / \mathrm{c}$ ratio could appear again.

\section{CONCLUSION}

Solid phase percolation (solid grain contact) has been compared to mechanical percolation (material cohesion). For this comparison, cement paste microstructures have been generated randomly. The following conclusion can be drawn: 1. Solid phase percolation can not predict accurately mechanical threshold for cementitious materials. Indeed, solid grain contacts are not sufficient to bring the cohesion of the material: solid phase percolation can occur without any hydrated products. This is the case for low w/c ratio.

2. Cement paste microstructures have been used to generate finite elements meshes. Finite elements simulations have proved that using interface elements can predict qualitatively the percolation threshold for cement pastes. For cement paste the w/c ratio affects the mechanical threshold.

3. Mortar microstructures have been generated. In the case of our mortar, the mechanical threshold is almost independent of the $w / c$ ratio and is lesser than the threshold of the cement paste with the same w/c ratio.

\section{Future work:}

Additional investigations have also to be performed. Threedimensional microstructures must be used, since percolation threshold differs from the one in two dimensions. Moreover, the microstructure is generated randomly. Comparison with "intelligent" ones (as CEMHYD3D [2] or HYMOSTRUC [5] for instance) is needed to underline the role playing by the construction algorithm of cement paste microstructure. Furthermore, material cohesion can be brought by capillary forces. This has not been taken out in this study.

The developed algorithm can be used to predict additional properties of cementitious materials, with some slight improvements, as: Young's modulus, Poisson's ratio, compressive and tensile strength, autogeneous and drying shrinkage, basic creep etc. The prediction of these properties is currently undertaken.

\section{REFERENCES}

[1] Acker, P., 'Comportement mécanique du béton : apports de l'approche physico-chimique', Thèse de doctorat, Ecole Nationale des Ponts et Chaussées, France (1988).

[2] Bentz, D.P., 'CEMHYD3D: a three-dimensional cement hydration and microstructure development modelling package, version 2.0.', NISTIR 6485, U.S. Department of Commerce, (April 2000) (available at http://ciks.cbt.nist.gov/monograph).

[3] Bernard, O., UIm, F.J. and Lemarchand, E., 'A multiscale micromechanics-hydration model for the early-age elastic properties of cement-based materials', Cem. Conc. Res. 33 (9) (2003) 1293-1309.

[4] Boumiz, A., Vernet, C. and Cohen Tenoudji, F. 'Mechanical properties of cement pastes and mortars at early ages Evolution with time and degree of hydration', Advn Cem Bas Mat 3 (3-4) (1996) 94-106.

[5] van Breugel, K., 'Simulation of hydration and formation of structure in hardening cement-based materials', $\mathrm{PhD}$ Thesis, Technical University Delft, Netherlands (1997).

[6] Byfors, J., 'Plain concrete at early ages', PhD Thesis, Swedish cement and concrete institute, Sweden (1980).

[7] Chen, Y. and Odler, I., 'On the origin of Portland cement setting', Cem. Conc. Res. 22 (1992) 1130-1140.

[8] Dovzhenko, A.Y. and Zhirkov, P.V., 'The effect of particle size distribution on the formation of percolation clusters', Physics letters A 204 (3-4) (1995) 247-250.

[9] Garboczi, E.J., and Bentz, D.P., 'The microstructure of portland cement-based materials: computer simulation and percolation theory', in 'Computational and mathematical models of microstructural evolution', Materials Research Society Symposium Proceedings, San Francisco, April 1998 (Materials Research Society, Pittsburgh, 1998) 89-100.

[10] Garboczi, E.J., Bentz, D.P., Snyder, K.A., Martys, N.S., Stutzman, P.E., Ferraris, C.F. and Bullard, J.W., 'An electronic monograph: Modelling and measuring the structure and properties of cement-based materials', http://ciks.cbt.nist.gov/garbocz/, (2003).

[11] de Schutter, G. and Taerwe, L., 'Degree of hydration-based description of mechanical properties of early age concrete', Mater. Struct. 29 (1996) 335-344.

[12] Thinet, S., 'Mesures rhéologiques sur matériaux évolutifs hétérogènes par propagation d'ondes acoustiques', Thèse de doctorat, INSA de Lyon, France (2000).

[13] Torrenti, J.-M., 'La résistance du béton au jeune âge', Bulletin de Liaison des LPC 179 (1992) 31-41.

[14] Velez, K., Maximilien, S., Damidot, D., Fantozzi, G. and Sorrentino, F., 'Determination of elastic modulus and hardness of pure constituents of Portland cement clinker', Cem. Conc. Res. 31 (4) (2001) 555-561. 